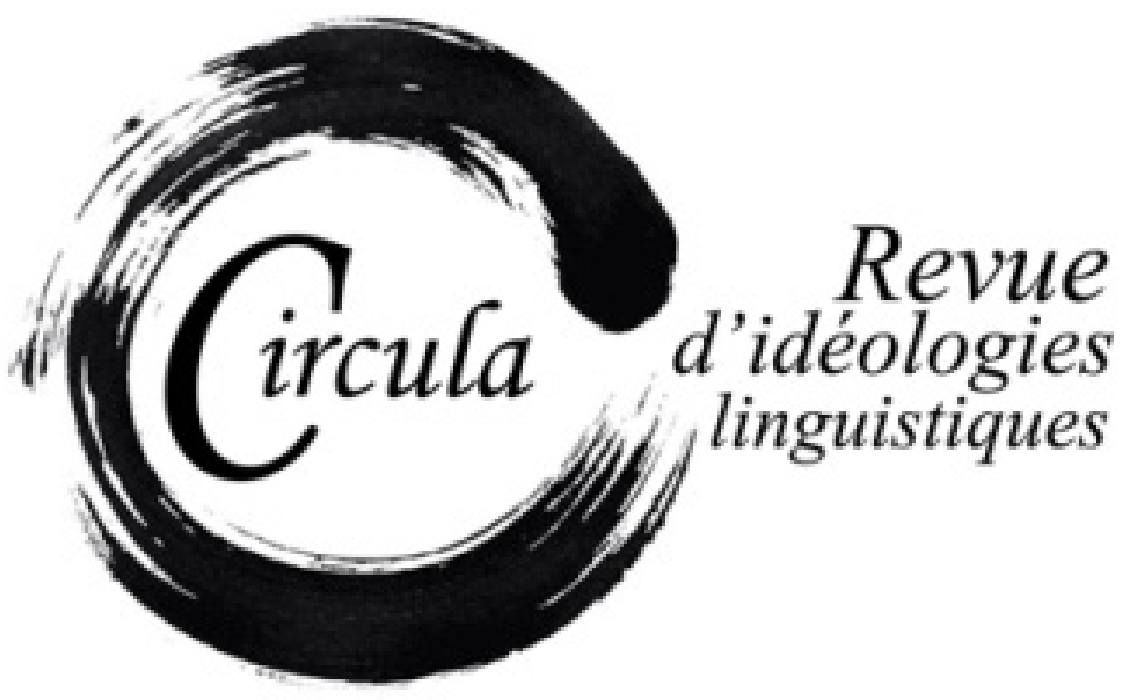

TITRE: INTERVENCIONES SOBRE LA LENGUA EN LA ARGENTINA DE FINALES DE LOS 1920: Babel y EL CASTELLANo (1928) DE ARTURO CAPDEVILA, ENTRE LA PRENSA Y EL LIBRO Auteur: JuAn Antonio EnNis, CONICET-Universidad Nacional de LA PLATA Revue: CIRCULA, NUMÉRO 11

PAgES: $1-23$

ISSN: 2369-6761

URI: HTTP://HDL.HANDLE.NET/11143/17838

DOI: HTTPS://DOI.ORG/10.17118/11143/17838 


\section{Intervenciones sobre la lengua en la Argentina de finales de los 1920: Babel y el castellano (1928) de Arturo Capdevila, entre la prensa y el libro}

Juan Antonio Ennis, CONICET-Universidad Nacional de La Plata juanennis@ conicet.gov.ar

Resumen: El presente trabajo propone un recorrido por una obra particularmente influyente en la historia de los debates so bre la lengua en Argentina: Babel y el castellano (1928), de Arturo Capdevila, considerándola desde su gestación en las columnas publicadas por su autor en el periódico La Prensa de Buenos Aires a partir de 1925. El análisis atiende asimismo a la articulación que estas intervenciones, por parte de un escritor versátil aunque lego en materia de ciencias del lenguaje, encuentran en sus distintas manifestaciones con campos y discursos en proceso de consolidación y diferenciación en la época en el país, como el de la literatura y los estudios lingüísticos, así como a los ecos que estas hallan en desarrollos posteriores, especialmente en el campo de la lingüística profesional.

Palabras clave: debates ideológico-lingüísticos; Argentina; Arturo Capdevila; prensa periódica

Abstract: The following paper attempts to give an insight into a particularly influential work in the history of language-ideological debates in Argentina: Babely el castellano (1928), by Arturo Capdevila, considering it from its very origin in the columns published by its author in the Buenos Aires' newspaper La Prensa from 1925 to 1927. The analysis also points to the way in which these interventions by a versatile writer -although a layman in the field of language sciences- deal with fields and discourses which were going through several processes of consolidation and differentiation in Argentina at the time (such as literature and linguistic studies). It also highlights the echoes that Capdevila's texts find in later developments, especially in the field of professional linguistics.

Keywords: language-ideological debates; Argentina; Arturo Capdevila; periodical press 


\section{Introducción: escenarios compartidos ${ }^{1}$}

En 1962, la Academia Argentina de Letras recibió en su seno a Jorge Luis Borges, por entonces ya un escritor mundialmente reconocido, que entre otras cosas acababa de recibir el premio Formentor, compartido con Samuel Beckett. El testimonio de su recepción, publicado en el tomo XXVII del Boletín de dicha institución, sigue el paso ceremonial de rigor, con un miembro que invita con su discurso la apertura del propio de quien acaba de ser designado. El encargado de esa recepción fue Arturo Capdevila, abogado, poeta y ensayista cordobés de gran reputación en la primera parte del siglo XX y escasa memoria en la historia literaria actual. En su breve presentación, Capdevila llama a Borges "gran señor de las letras, gran señor del idioma" (1962: 297), y sitúa la aparición providencial de su literatura en el contexto de la doble herencia de la que todo escritor local gozaría: por la tradición española acarreada por la sangre, por un lado, y la apropiada en suelo americano, por el otro. Seguidamente, pondera la novedad de la obra de Borges comenzando con la siguiente observación: "Toda nueva generación viene a descubrir el mundo. ¡Mirad el sol! ¡Mirad las estrellas! ¡Contemplad la fiesta de las nubes que pasan!’” (Capdevila 1962: 298). Llama la atención en su discurso la opción por la variante peninsular de la segunda persona del plural, que en ese entonces se restringía probablemente a no mucho más allá de los manuales escolares y los discursos de Capdevila. Borges, por su parte, al comenzar su conferencia, que abundaría sobre la afinidad entre el concepto de la academia y el remoto mundo de los celtas, recordaría que al oír el primer término se tendería a pensar en primer lugar "en la policía del lenguaje, en las autorizaciones o prohibiciones de palabras, todo esto es bastante baladí, ya lo sabemos todos" (Borges, 1962: 303).

No era la primera vez que Borges mostraba su menosprecio por la banalidad del ejercicio de limpieza purista al que se abocaban las Academias, y en especial la española. Tampoco era la primera vez que lo hacía compartiendo escenario con Arturo Capdevila. Treinta y cinco años antes había tenido lugar una de las más célebres intervenciones del enonces joven y promisorio escritor argentino, tal como lo había anunciado entonces el periódico La Prensa, al publicitar la conferencia en su edición del 21 de septiembre de 1927. No es uno de los objetivos de este trabajo analizar el contenido de la conferencia (que ya cuenta con estudios muy completos ${ }^{2}$ ), sino solamente describir el escenario en que tiene lugar, como extensión de un espacio de intervención pública paralelo a los más restringidos círculos literarios y académicos, aunque de gran popularidad y prestigio.

En ese momento, había en Argentina cuatro periódicos que podían considerarse en la categoría moderna de los grandes diarios, por la magnitud de su tirada, la amplitud nacional de su alcance "y un emplazamiento social tan significativo como amplio y complejo": La Prensa, La Nación, La Razón y Crítica (Gómez 2008). Como se ocupa de referir Saítta (2013: 73), el primero de estos periódicos, el

1. Este trabajo guarda una deuda de gratitud con Guillermo Toscano y García, cuyos comentarios y observaciones resultaron sumamente enriquecedores en la redacción final. Las falencias, por supuesto, son responsabilidad del autor.

2. Resulta sobre todo recomendable, para el análisis tanto de la escena como del propio texto y sus implicancias el muy completo trabajo de Fernando Degiovanni y Guillermo Toscano y García (2010a y b). 
más antiguo de ellos (había sido fundado en 1869), tenía mediando los años 1920 una presencia en la vida pública de la capital argentina y más allá de ella que no se limitaba a su notable tirada de 230000 ejemplares diarios, ni a las 36 páginas que alcanzaban los mismos en la semana (64 páginas los domingos), y a lo concurridas que resultaban sus páginas de avisos (Saítta recuerda que el 6 de noviembre de 1924 el periódico bate el récord de 6312 avisos, y dos años después, según nuestra propia constatación, el 7 de noviembre de 1926, se registra la superación de esa marca), sino que además ofrecía a sus lectores una serie de servicios gratuitos, entre los que destacaba -además de servicios sanitarios y legales, biblioteca y otros- el Instituto Popular de Conferencias, fundado el 18 de julio de 1914.

El objetivo del Instituto Popular de Conferencias de La Prensa era el de generar un espacio de difusión de saber especializado de relevancia pública, por fuera de las instituciones académicas oficiales e independiente de adscripciones políticas o religiosas definidas. Afirmado en su rol de orientador de la opinión (Gómez, 2008: 69), el periódico procuraba de este modo ampliar su porción de espacio público, reclamando para sí un lugar, que si bien no venía a competir con el de la universidad, sí decía complementarla. Tal como consta en el acta fundacional del Instituto, el director de La Prensa, Ezequiel P. Paz, habría manifestado lo siguiente a su primera Comisión:

Es mi propósito, y para eso os he llamado y solicitado concurso, fundar un centro de difusión y cultura, que, al par que atestigüe la potencia intelectual de nuestra raza, contribuya a fomentar la educación espiritual del pueblo en forma amena y sintética de conferencias selectas, dando de este modo a los espíritus ávidos de emociones desinteresadas, tras los desasosiegos de la lucha diaria, solaz y esparcimiento en lo más noble y puro, las ciencias y las artes: y sin tolerar límites al anhelo, aspirar en los grandes momentos, y aún durante el curso tranquilo de los acontecimientos, a propiciar orientaciones sobre los grandes problemas nacionales y humanos, sean circunstanciales o permanentes. (Zeballos, 1915: 4)

Las conferencias tenían lugar en el fastuoso salón de actos del segundo piso del edificio -réplica de uno de los salones del Palacio de Versalles (Gómez, 2008: 265) - y eran publicadas en lugares centrales y visibles del periódico (primera plana o páginas centrales) al día siguiente. La de Borges del 23 de septiembre de 1927 no sería la excepción, apareciendo a doble página el 24, con una descripción detenida de la concurrencia y las circunstancias, así como del aval prestado por distintas personalidades de la filología institucionalizada y publicística a través de su presencia en el escenario. Borges no asistiría personalmente, sino que Manuel Rojas Silveyra hará lectura de su discurso, en presencia de un nutrido público y personalidades relevantes de la cultura (v. Degiovanni y Toscano y García 2010), el mismo que al año siguiente coronaría el volumen que llevaba igual título: El idioma de los argentinos (1928). El presentador, también entonces, era Capdevila, vocal de la institución. 
En las páginas del mismo periódico, Borges y Capdevila compartían en la misma época asimismo un espacio de especial visibilidad. La segunda sección dominical de La Prensa albergaba columnas de materia literaria, artística, científica y cultural de reconocidas firmas del campo intelectual local y europeo. De presencia constante eran los nombres de los españoles Azorín, Manuel de Montoliu, Ramón Pérez de Ayala, Ramiro de Maeztu, el argentino Sáenz Hayes, entre otros; de regular aparición (al menos entre 1925 y 1928, período relevado en el presente trabajo) los de Borges, Capdevila, Rafael Alberto Arrieta, José Imbelloni, Juan B. Terán, Víctor Mercante, Robert Lehmann-Nitsche, Luis Franco, Máximo Soto Hall, Ricardo Sáenz Hayes, o intelectuales de fama internacional como Benedetto Croce o Marcel Prevost, entre otros. La controversia glotopolítica soterrada que se insinúa en la presentación académica -entre la notoria persistencia en el uso del "vosotros" y el carácter baladí de la policía lingüística académica- podría recuperarse sin más en las páginas de La Prensa, probablemente no como enfrentamiento abierto, sino como sencilla copresencia. Entre sus intervenciones sobre temas de estética e historia literaria, Borges había publicado en esta segunda sección de este periódico algunas de sus intervenciones previas a la conferencia en torno a la discusión por el idioma, trabajos que aparecerían sobre todo en sus volúmenes de ensayos El tamaño de mi esperanza (1926) y El idioma de los argentinos (1928). Se trata, por ejemplo de "Carriego y el sentido del arrabal" (4 de abril de 1926), "Acerca del vocabulario" (2 de mayo de 1926) o "Invectiva contra el arrabalero" (6 de junio de 1926). En este punto, los trabajos de Borges forman parte de un conjunto más amplio de publicaciones que a finales de los años 20 proliferan en la prensa periódica y cultural de Buenos Aires, configurando uno de los momentos más intensos en la historia de los debates sobre la lengua en Argentina. ${ }^{3}$

Capdevila, por su parte, entre sus columnas de temática asimismo literaria, o en torno a sus viajes por el país y la Península ibérica, daría a conocer en esta sección del periódico los trabajos que luego se integrarán en un volumen de larga trayectoria en el panorama glotopolítico argentino, Babel y el castellano (1928). Este libro, publicado por primera vez por la editorial Cabaut en Buenos Aires y distinguido con el Premio Nacional de Literatura en 1931, representa una intervención efectiva y duradera en el debate glotopolítico. Fue reeditado por Losada en 1940 (llegando a una tercera edición en esta misma casa en 1954), y también por la breve pero prestigiosa Compañía Ibero-Americana de Publicaciones con sede en Madrid, Barcelona y Buenos Aires (López Morel y Molina-Abril 2012) (esta edición carece de fecha). En referencia a su edición en Losada, Glozman (2015: 40) señala su lugar en una serie de publicaciones impulsada por Amado Alonso en esta pujante editorial, serie en la que se combinaba la difusión del saber lingüístico especializado y la discusión sobre la lengua, y en la cual al de Capdevila le seguirían volúmenes de gran impacto como La peculiaridad lingüística rioplatense y su sentido histórico (1941) de Américo Castro o Castellano, español, idioma nacional, del propio Amado Alonso (1943). Esta edición de Babel y el castellano vendría acompañada de sen-

3. Se reconoce así, por ejemplo, de acuerdo con las distintas perspectivas, en 1927 (Toscano y García 2019) y 1928 (Alfón 2013) los momentos claves de la polémica. Asimismo, dentro del proyecto en cuyo marco se desarrolla esta investigación (PICT 2017-1865: “Ideologías lingüísticas en la prensa escrita en Argentina, 1810-1855”) se está estudiando también otra serie, presente en La Prensa de la época, las “Gramaticales y filológicas” redactadas primero por Matías Calandrelli y luego por Florencio Garrigós (investigación a cargo de Esteban Lidgett y Guillermo Toscano y García). 
dos paratextos firmados por reconocidos escritores españoles de larga presencia en la prensa y el mercado editorial argentinos. El "Prólogo con versos" consistía en una carta de Miguel de Unamuno fechada el 31 de agosto de 1928, luego de haber recibido el ejemplar de Babel y el castellano que le remitiera su autor, y en la que agregaba dos poemas dedicados a él, que anunciaba irían incluidos en su poemario En la frontera (el Cancionero de su destierro en Hendaya, que no llegaría a publicar en vida). Como corolario del volumen, se reproducía parcialmente una nota de Guillermo de Torre, publicada el 5 de junio de 1932 en el folletón de la octava página de El Sol de Madrid. Originalmente titulado "Nuestro idioma y la Argentina", el artículo de De Torre, transformado en epílogo del libro reseñado, adquiría el nombre más elogioso de "La buena doctrina". Celebrando la defensa de la unidad del idioma con centro en Madrid realizada por Capdevila, De Torre denigra con él las diversas formas de nacionalismo lingüístico estereotípicas entonces para la Argentina, y se apoya sobre todo en la ya referida conferencia de Borges para reforzar sus argumentos.

Capdevila, lo mismo que Borges, no intervenía en la discusión como especialista acreditado por títulos académicos - un tipo de agente novedoso aunque ya asentado y visible de manera decisiva en el campo intelectual argentino y en las páginas de la prensa periódica y cultural (Toscano y García, 2009) - o reconocido por su expertise autodidacta al estilo de Arturo Costa Álvarez (Degiovanni y Toscano y García, 2010; Toscano y García, 2016; Ennis, en prensa). Sin embargo, lo que diferencia asimismo su intervención como literato de otras más próximas a la discusión de orden estético es la frecuencia del recurso a la autoridad de la cita filológica y de la historia lingüística, en un tono que combina el ensayo y la interpelación al lector con argumentaciones de índole diversa, siempre orientadas a la promoción de la unidad de la lengua española con centro en Castilla.

Esto quiere decir también que la serie de columnas que Capdevila publica en La Prensa y dan forma a un libro de intervención glotopolítica de eficacia tan duradera como se ha consignado más arriba, si bien cobra forma en las intervenciones periódicas de un letrado en materia de lenguaje, no proviene estrictamente de un espacio que podamos asociar a la chronaque linguistique en sentido estricto -ya que no se trata de un espacio asociado regularmente al tema- sino de la integración de la temática en el espacio del periódico, más precisamente en el de una firma de aparición regular en el espacio destinado a la literatura, la ciencia y la cultura en general, que contaba entre sus temas no el de la mera censura de usos inadecuados, sino reflexiones que invocaban la autoridad del discurso científico para proponer políticas lingüísticas de cierta precisión. ${ }^{4}$

Capdevila, entonces, no era ni un filólogo ni un gramático, sino un poeta y publicista de intereses y osadías múltiples. En su bosquejo biográfico lo retrata así Fermín Estrella Gutiérrez (1961: 26):

\footnotetext{
4. Remysen define la columna sobre la lengua del siguiente modo: "ensemble de discours sur la langue, plus particulièrement encore sur les bons et les mauvais usages de la langue. Elle est diffusée périodiquement sous forme de rubriques dans les médias écrits (articles de journal ou de revue) ou électroniques (émissions de radio ou de télévision). La chronique est signée par une même personne, physique ou morale, à laquelle on reconnaît une compétence en matière de langue" (Remysen, 2005, p. 271, cf. también Gagné et al., 2004, Remysen, 2009; Meier y Schwarze, 2020).
} 
Todo lo ha abarcado este hombre del Renacimiento, surgido como un milagro entre nosotros, en estos tiempos de la especialización y de la concentración rigurosa en una u otra disciplina. Pareciera como si él mismo no hubiera podido sustraerse a este destino múltiple y al parecer heterogéneo e incontrolado, de su ingente obra de creación.

Era abogado, había sido juez en su Córdoba natal, y estaba dedicado desde entonces a una carrera literaria que le había granjeado ya en 1920 y 1923 el Premio Nacional de Literatura, y en 1922 su ingreso a la Academia Nacional de la Historia. Al final de la primera edición del volumen se agrega una nota que menciona su incorporación como académico correspondiente a la RAE:

Este libro se imprimió en la Imprenta Mercatali (Avda. Acoyte, N. 271, Buenos Aires) y fue entregado a los libreros corriendo el mes de julio de 1928. Y por esos mismos días su autor fue designado miembro correspondiente de la Real Academia Española; siendo bueno que conste aquí, en mérito de cada uno, que ni el autor escribió este libro para que lo nombrasen académico, ni lo nombraron porque lo escribiera. (Capdevila, 1928: 191)5

La publicación en 1952 en Losada de Despeñaderos del habla, poco antes de la tercera edición de Babel y el castellano (1954), y luego de Consultorio gramatical de urgencia (1967) en la misma editorial, da cuenta de la persistencia del autor en estos afanes, así como de la sostenida vigencia de los mismos en el mercado del libro y, probablemente, también entre el público lector.

\section{El libro y los artículos}

El presente trabajo se propone como objetivo ofrecer un examen de las intervenciones de Arturo Capdevila en el periódico La Prensa entre 1925 y 1928, que desembocarán en su puesta en volumen en Babel y el castellano. El análisis de estos textos se realiza aquí tomando en consideración el modo en que los mismos se inscriben tanto en su contexto inmediato de publicación -caracterizado por un particularmente intenso debate glotopolítico- como en una tradición de debates sobre la lengua, que no solamente recuperan, sino que logran además imprimir una huella duradera en ella. De este modo, se pretende ofrecer un aporte al conocimiento de una zona específica del archivo de la que con Del Valle (2015) podemos Ilamar historia política del español, aquí específicamente en Argentina, que procure dar cuenta de las condiciones materiales de su emergencia y el complejo entramado de su circulación y recepción en distintos tiempos y ámbitos.

Babel y el castellano, así, es el libro de un escritor reconocido que a partir de 1925 comienza a dar lugar recurrentemente en sus columnas al debate histórico sobre la lengua en Argentina. El libro, el más conocido en esta materia de un autor ubicado en la línea del "nacionalismo de corte hispánico" (Di Tullio, 2003: 101), había sido precedido en 1925 por otro, sobre la base de textos previamente

5. En "La prodigiosa y díscola ciudad del idioma común" (La Prensa, 12 de junio de 1927), Capdevila lamentaba la falta de reciprocidad entre españoles y americanos a la hora del intercambio intelectual, refiriendo la escasa recepción del envío de docenas de ejemplares de Tierras nobles "a colegas y a periódicos"; quizás esta haya sido una forma de respuesta. 
aparecidos en La Prensa, que bajo el título de Tierras nobles. Viajes por España y Portugal (Buenos Aires, El Ateneo, 1925), desplegaba asimismo un panegírico de la madre patria.

Babel y el castellano reúne intervenciones de tres órdenes: en favor de la unidad del idioma, con centro en Castilla; en contra del voseo en Argentina, así como de las entonces nuevamente activas intervenciones en favor de una gestión autónoma de la identidad y la diferencia lingüística en Argentina, y también observaciones acerca de la lengua de los sefardíes, encomiando claro está la lealtad lingüística de estas comunidades para con el español.

En el siguiente cuadro se consignan los distintos capítulos que componen el volumen, junto con su fecha de publicación primera en La Prensa, el título original y algunas observaciones acerca de las variantes encontradas.

\begin{tabular}{|c|c|c|c|c|}
\hline $\begin{array}{l}\text { Número de } \\
\text { capítulo }\end{array}$ & $\begin{array}{c}\text { Título en Babel y el } \\
\text { castellano }\end{array}$ & $\begin{array}{c}\text { Título en La } \\
\text { Prensa }\end{array}$ & Fecha de publicación & Observaciones \\
\hline I & $\begin{array}{l}\text { Un gran imperio } \\
\text { espiritual }\end{array}$ & $\begin{array}{l}\text { Meditaciones } \\
\text { sobre el idioma } \\
\text { castellano }\end{array}$ & $\begin{array}{c}\text { Domingo } 27 \text { de diciembre } \\
\text { de } 1925\end{array}$ & $\begin{array}{l}\text { Se añaden algunos pá- } \\
\text { rrafos autobiográficos } \\
\text { en la última parte (pp. } \\
\text { 23-24 de la } 1^{2} \text { ed.) }\end{array}$ \\
\hline ॥ & La utopía & $\begin{array}{l}\text { Meditaciones } \\
\text { sobre el idioma } \\
\text { castellano }\end{array}$ & Viernes 1 de enero de 1926 & \\
\hline III & España y América & $\begin{array}{l}\text { Meditaciones } \\
\text { sobre el idioma } \\
\text { castellano }\end{array}$ & $\begin{array}{c}\text { Domingo } 17 \text { de enero de } \\
1926\end{array}$ & $\begin{array}{c}\text { En las ediciones pos- } \\
\text { teriores en Losada se } \\
\text { añade una nota con } \\
\text { respecto a la situación } \\
\text { del mercado editorial } \\
\text { tras la Guerra Civil } \\
\text { española. }\end{array}$ \\
\hline IV & En Castilla & En Castilla & $\begin{array}{c}\text { Sábado } 1 \text { de enero de } \\
1927\end{array}$ & \\
\hline V & $\begin{array}{c}\text { El embrollado problema } \\
\text { del tú y el vos }\end{array}$ & $\begin{array}{l}\text { El embrollado } \\
\text { problema del tú y } \\
\text { el vos }\end{array}$ & $\begin{array}{l}\text { Domingo } 16 \text { de enero de } \\
1927\end{array}$ & \\
\hline $\mathrm{Vl}$ & $\begin{array}{c}\text { El tú y el vos en los } \\
\text { clásicos }\end{array}$ & $\begin{array}{l}\text { El tú y el vos en } \\
\text { los clásicos }\end{array}$ & $\begin{array}{c}\text { Domingo } 13 \text { de febrero de } \\
1927\end{array}$ & \\
\hline VII & El tú y el vos en América & $\begin{array}{l}\text { El tú y el vos en } \\
\text { América }\end{array}$ & $\begin{array}{c}\text { Domingo } 20 \text { de febrero de } \\
1927\end{array}$ & \\
\hline VIII & El idioma en la Argentina & $\begin{array}{l}\text { El idioma en la } \\
\text { Argentina }\end{array}$ & $\begin{array}{c}\text { Domingo } 24 \text { de abril de } \\
1927\end{array}$ & $\begin{array}{l}\text { Coincide con el "día del } \\
\text { idioma" y el falleci- } \\
\text { miento de R. Monner } \\
\text { Sans }\end{array}$ \\
\hline
\end{tabular}




\begin{tabular}{|c|c|c|c|c|}
\hline $\begin{array}{l}\text { Número de } \\
\text { capítulo }\end{array}$ & $\begin{array}{l}\text { Título en Babel y el } \\
\text { castellano }\end{array}$ & $\begin{array}{l}\text { Título en La } \\
\quad \text { Prensa }\end{array}$ & Fecha de publicación & Observaciones \\
\hline IX & Los sefardíes & & & \\
\hline$x$ & El romancero sefardí & $\begin{array}{l}\text { El castellano de } \\
\text { los sefardíes, su } \\
\text { romance }\end{array}$ & $\begin{array}{l}\text { Domingo } 14 \text { de febrero de } \\
1926\end{array}$ & $\begin{array}{c}\text { La sección II de la edi- } \\
\text { ción en libro no está en } \\
\text { la edición en periódico } \\
\text { Intercala en la sección } \\
\text { I la mención a Wagner } \\
\text { (1914) }\end{array}$ \\
\hline$X I$ & $\begin{array}{c}\text { En Manila se ha puesto } \\
\text { el sol }\end{array}$ & $\begin{array}{l}\text { En Manila se ha } \\
\text { puesto el sol }\end{array}$ & $\begin{array}{c}\text { Domingo } 18 \text { de julio de } \\
1926\end{array}$ & \\
\hline XII & $\begin{array}{l}\text { La prodigiosa y díscola } \\
\text { ciudad del idioma común }\end{array}$ & $\begin{array}{l}\text { La prodigiosa y } \\
\text { díscola ciudad del } \\
\text { idioma común }\end{array}$ & $\begin{array}{c}\text { Domingo } 12 \text { de junio de } \\
1927\end{array}$ & \\
\hline XIII & $\begin{array}{l}\text { El inmenso mar del } \\
\text { castellano }\end{array}$ & $\begin{array}{l}\text { El inmenso mar } \\
\text { del castellano }\end{array}$ & $\begin{array}{c}\text { Domingo } 29 \text { de mayo de } \\
1927\end{array}$ & \\
\hline
\end{tabular}

Hasta el capítulo VIII se mantiene la correspondencia entre la sucesión de los capítulos y el orden cronológico de su aparición en el periódico. Como puede verse en las "Observaciones" de la última columna del cuadro, las variaciones son mínimas entre una y otra aparición. Sólo en el caso de "Los sefardíes" no he podido dar con su antecedente en La Prensa.

Los primeros tres capítulos aparecieron sucesivamente, los días 27 de diciembre de 1925, 1 y 17 de enero de 1926, siempre bajo el mismo título de "Meditaciones sobre el idioma castellano", que varía luego en el libro. En ellos se celebra la unidad de la lengua tal como venía haciéndose desde el comienzo de la política panhispánica encarada por la Academia al menos desde el ingreso de Juan Valera en 1862, recapitulando la historia de los debates sobre la lengua en Argentina, y subrayando, al igual que su fuente (Costa Álvarez, 1922), el carácter extendido de pecado de juventud que definiría el secesionismo lingüístico de la generación del 37.6 El segundo se ocupa de rebatir con argumentos diversos la necesidad de un idioma nacional para los argentinos, cerrando con una afirmación de la profunda identidad entre España y la Argentina fundada en el parentesco entre el Himno nacional argentino y el "Canto guerrero para los asturianos" de Gaspar Melchor de Jovellanos, señalada por Menéndez y Pelayo en su Historia de la poesía Hispanoamericana de 1911 (1948: 334).

6. El mismo Costa Álvarez, no obstante, le dedicaría una reseña especialmente crítica, poniendo límites justamente al alcance de este tipo de representaciones: "A mí me parece que los argentinos no nos hemos emancipado para andar requiriendo la tutela espiritual de la madre patria, como la criatura que se arrepiente de alguna rebeldía; y me parece también que es un acto poco digno de un pueblo libre transferir a otro pueblo la tarea de velar por su propia lengua y por su propia influencia" (Costa Álvarez, 1928: 288). 
El tercer artículo de este bloque inicial pasa de la celebración a la promoción económico-política de la unidad de la lengua, retomando el tópico -habitual también desde finales del XIX- de la incomunicación entre la producción letrada no sólo a uno y otro lado del Océano, sino sobre todo entre los países americanos, traduciendo lo que sería poco después una discusión por el meridiano intelectual (de Torre, 1927, v. Falcón, 2010a y b; Bosoer, 2008, Alemany, 1998; entre otros) en la más clara de -como se lo llamó posteriormente- un meridiano editorial:

Una vasta empresa editorial de obras en habla española, radicada en Madrid o en BarceIona, es cosa de suma urgencia. Agrego que tiene que ser un buen negocio. En cien años de literatura continental hay veinte o más autores dignos de difusión por el continente y la península. Es un absurdo el acantonamiento en que vivimos. No debe ser tolerado por más tiempo que un escritor del Perú o de la Argentina se reduzca a ser leído por sus compatriotas. No conozco un feudalismo más necio. Resultado: cifras humillantes e irrisorias. 1.500 acaso 2.000 ejemplares por todo tirar... irrisorio y humillante. jHay que haber nacido con misión de escribir para seguir escribiendo! (Capdevila, 1928: 53)

En la sección de la reseña de De Torre en El Sol no incorporada al epílogo de Babel y el castellano en su edición de Losada, este autor subrayaba de hecho esta como una reivindicación de su combatida propuesta (combatida entre otros por el propio Borges, v. Ennis 2008: 236), que generaría en 1927 la célebre polémica sobre Madrid como meridiano intelectual de Hispanoamérica: "No se trataba, empero, sino de poner en un pie de igualdad ante el mercado la producción española y la hispanoamericana; de otorgar a esta última el mismo trato de publicidad y de atención que merece ahí la nuestra. Y ése era, en definitiva-repito una vez más-, el supremo vértice adonde apuntaba aquella desnaturalizada pretensión del meridiano, no cultural, sino editorial, publicitario, empírico" (De Torre, 1932). En este punto cabe destacar el acierto de Falcón (2010) al resaltar a Babel y el castellano entre los "discursos sobre el llamado 'problema de la lengua en América" que "revelan los fundamentos económicos de las creencias lingüístico-culturales que procuran instalar", esto es, la expansión americana del mercado editorial español. El de la unidad de la lengua es un problema estratégico de un "nosotros" que debía encontrar en el mercado del libro un agente de cohesión y progreso:

Nadie se queje si mañana los yanquis se apoderan de esa formidable llave de las rutas del pensamiento hispanoamericano. Nadie se queje si mañana España pierde otro inexpugnable Gibraltar, desde el cual gobierne un extranjero invasor todas las corrientes editoriales del mundo hispánico: quiero decir nuestros sentimientos, nuestras ideas, nuestros anhelos, nuestra acción, dueños y señores de todo libro y árbitros de la real eficiencia de todo autor. (Capdevila, 1928: 54-55)

La única variación que se encuentra entre la edición en periódico y la edición en libro consiste en la actualización de la fecha del que probablemente constituya su postulado central (y también el de todo el libro), que pone de manifiesto el lugar que se otorgaba a la lengua en el discurso acerca de 
su unidad como avatar de un proceso de secularización en el cual la universalidad de la democracia liberal se daba también por fracasada:

Desnuda verdad fechada en 1928 [1926 en la primera versión]: no cuenta la América española con otra unidad que la del común idioma. La unidad religiosa no tiene ninguna eficacia actual (ni existe), y en cuanto a la unidad del régimen político, muchos de sus pueblos han renegado del inmenso bien de la democracia, ya que la dejaron ofender y profanar por menguados tiranuelos. No queda más que el idioma. (Capdevila, 1928: 50)

La postura de Capdevila coincidía aquí políticamente con la esgrimida entonces de diverso modo por los sucesivos representantes del Centro de Estudios Históricos madrileño en Buenos Aires. Si bien presentarían rasgos diferenciales individuales significativos, tanto Américo Castro como Amado Alonso promoverían en sus escritos más significativos una representación restrictiva de la lengua legítima y una mirada crítica sobre la relación entre la norma lingüística, la estratificación social y la cultura de masas en Argentina, fuertemente arraigada en el Ortega y Gasset de La rebelión de las masas (Ennis, 2008: 249; Arnoux y Bein, 1995: 190-191).

El cuarto ensayo -acompañado en el periódico por fotografías de la catedral y el alcázar de Segovia y la puerta de Fernán González en Burgos- funciona como reenvío al libro anterior, Tierras Nobles, postulando a Castilla como la Meca o "tierra santa de este portento", de un idioma tratado en la retórica cuasi-religiosa de la comunidad espiritual, incorporando el motivo recurrente hasta hoy de la creciente cantidad de hablantes del castellano: "No ha mucho, se calculaba en 85000000 la cifra de los que hablamos castellano por haberlo recibido en la materna leche. Ahora, la cifra debe rectificarse y ser elevada a más de los 90000 000. El castellano está triunfante en el mundo, y es una de las mayores fuerzas del espíritu sobre la tierra" (Capdevila, 1928: 59). Volviendo sobre la resignificación del canon liberal decimonónico, esta vez al releer los Viajes de Domingo F. Sarmiento por España, reivindica -como ya lo hacía Miguel de Unamuno (Ennis, 2008: 219)- el casticismo de la prosa de este último, para sostener en la anecdótica existencia de The Southern Star/La Estrella del Sur en Montevideo durante las invasiones inglesas de 1807 la superioridad, en los liberales que luego promoverían la emancipación, de la devoción por la lengua heredada sobre las convicciones políticas (Capdevila, 1928: 65).

Los siguientes cuatro artículos, publicados en La Prensa entre enero y abril de 1927, conforman un bloque sólido y quizás el verdadero núcleo de la intervención glotopolítica de Capdevila a través de la prensa y el libro. En ellos se abunda en lo que se ha descripto como su "fervorosa estigmatización del voseo" (Sztrum, 1992: 70), en un análisis de la historia y extensión de lo que entiende como "viruela del idioma" (Capdevila, 1928: 75), "cosa tan sucia" (ibid.: 107), "ignominiosa fealdad" (ibid.: 115), y que pretendía aún entonces desplazar del uso general a través del disciplinamiento del uso letrado y escolar. En la primera de estas columnas, "El embrollado problema del tú y el vos", presenta el tema indicándolo como una de las cuestiones de interés en materia lingüística para los hispanoamericanos, puesto que es de las que "conciernen a la suerte del castellano en América”, 
y especialmente para "nosotros los argentinos, enfermos de este sucio mal, que ojalá no resulte incurable" (ibid.: 71). La actitud de Capdevila no era en absoluto aislada, sino que encontraba eco en un sistema educativo que no solamente seguía enseñando exclusivamente el paradigma tuteante, sino que además lo estigmatizaba activamente. ${ }^{7}$

Sin embargo, la persistencia y el fervor del encono de Capdevila no dejan de otorgarle un lugar preeminente en este panorama. Hacia el final de los 1960, María Beatriz Fontanella de Weinberg, pionera de la sociolingüística en Argentina (v. Ennis, 2008), comenzaría a dar forma a un volumen nutrido y consistente de estudios en diacronía y sincronía sobre el voseo bonaerense. Al elaborar el estado de la cuestión del tema, destaca la presencia de Babel y el castellano:

La historia del voseo en Buenos Aires es un tema que ha suscitado diversas interpretaciones a lo largo de varias décadas. Curiosamente, una obra que ha tenido vasto eco y que se cita con frecuencia sobre la cuestión es Babel y el castellano, volumen carente de un enfoque lingüístico, publicado por Arturo Capdevila en 1928. En este libro Capdevila se deja llevar por un apasionamiento purista, según el cual el voseo constituye un "calamitoso rasgo" y una "ignominiosa fealdad" que conduce al caos espiritual, y señala que el uso de vos es síntoma de incultura y barbarie. De acuerdo con esto, sostiene que tanto la clase culta de la generación de Mayo, como la del período rivadaviano, desconocía el voseo, y que el oscurantismo instaurado durante el gobierno de Rosas fue el responsable de su difusión (Fontanella de Weinberg, 1971: 495)

Lo curioso del "vasto eco" de la obra de Capdevila se explica seguidamente al completar el estado de la cuestión con firmas autorizadas por su formación y prestigio filológico y lingüístico, que sin embargo retomaban las hipótesis de Capdevila, apoyándose en sus escritos como fuente de autoridad: se trata de Américo Castro, discípulo de Ramón Menéndez Pidal y primer director en 1923 del Instituto de Filología de la Universidad de Buenos Aires, de Berta Elena Vidal de Battini, formada en sus estudios de doctorado en la misma institución y responsable de un importante estudio de campo sobre el español en la Argentina (1964), y -ya en trabajos posteriores donde Fontanella (1976: 14) retoma esta misma crítica-, también de Bertil Malmberg (1973). ${ }^{8}$

La hipótesis que Fontanella de Weinberg venía a rebatir entonces a través de la evidencia documental no tenía que ver directamente con las diatribas de Capdevila, sino con la fundamentación histórica que proporcionaba a las mismas, en la cual combinaba el ejercicio de cierta erudición filológica (o al menos de la demostración del conocimiento de fuentes filológicas y literarias) apoyada en los fundamentos literarios prototípicos de un duradero relato de la historia y la identidad nacional, propio del liberalismo argentino. Este relato -que hemos llegado a encontrar aún vigente en fuentes más

7. Como botón de muestra, Sztrum (1992: 70) recuerda "que aún en 1939 una circular del Consejo Nacional de Educación prohibía el uso del voseo 'y demás formas bárbaras' en las escuelas primarias”.

8. Esto ha sido trabajado más ampliamente en un estudio anterior (Ennis, 2008: 327-328). El recorrido de esta hipótesis es examinado en detalle por López García (2015: 54-55) y sobre todo por Carricaburo (1999). 
recientes (Benavides, 2003: 619) - situaba al gobierno de Juan Manuel de Rosas en Buenos Aires, entre 1829 y 1852, como un factor clave en la imposición del voseo, consecuente con su política populista antiliberal. Adoptando las formas más maniqueas de esta verdadera fábula de identidad (Ludmer 1999), Capdevila comenzaba por dar cuenta de la expansión del fenómeno a partir de la mayor o menor expansión de la cultura letrada en las respectivas regiones americanas:

México y Lima fueron y son las grandes metrópolis del tú y los mayores centros de su expansión. La causa queda averiguada. En Lima y en México, tal como ocurriera en España, la adopción del tú fue un fenómeno de cultura y buena crianza, al paso que en lo restante de América el triunfo del voseo en las masas populares no fue sino una imposición del general atraso. Y tanto fue cosa de cultura el tutearse y tanto lo sigue siendo, que aún allí donde prepondera el voseo, como en la Argentina, la gente de mayor alcurnia intelectual dice de tú cuando otros emplearían el vos: y lo propio acontece en todas las otras zonas infectas por el voseo en América.

¿Un ejemplo? Monner Sans nos le ofrece: “En casa de Mitre no entró nunca el vos”... pues, ¡cómo había de entrar cosa tan sucia en tan limpia casa” (Capdevila, 1928: 107)

El linaje de los Mitre (presidente argentino entre 1862 y 1868, escritor, historiador y fundador del periódico La Nación), quintaesencia de la aristocracia liberal argentina, aparece como bastión para una alteridad voseante que en Babel y el castellano encuentra su raíz histórica en un período que la misma historiografía presidida por Mitre situaba como el de la barbarie y la oscuridad que precede a la "organización nacional". Los textos de los que Capdevila toma sus muestras son ejemplos centrales de la figuración literaria de la barbarie rosista afianzados en el canon de la literatura romántica argentina: Amalia de José Mármol o El matadero de Esteban Echeverría. "La librea es para vosotros, esclavos, y no para hombres libres”, desafía Eduardo Belgrano a los federales en la novela de Mármol, y Capdevila subraya esa ocurrencia como posible evidencia de una eventual supervivencia en las clases ilustradas porteñas (en su exilio montevideano) de una forma desaparecida de toda América. Sin embargo, inmediatamente destaca que lo más posible es que esto no sea más que un uso limitado a la literatura, para expresar un desideratum a esa altura ya sorprendentemente extemporáneo:

De esta suerte, este lindísimo vosotros familiar, gracioso y noble, que tanto suena, y tan bien, por casi toda España, ha venido a ser en la Argentina y lo restante de América mero tratamiento de oratoria; y apenas si empieza a ocupar algún sitio en el buen lenguaje epistolar. Dolámonos de esa ausencia. La intimidad del hogar y el corro de la genuina amistad han perdido sus más propios y fervorosos elementos de expresión. Ustedes: he ahí un vocativo frío, todo convencional, todo tercera persona... Vosotros: he ahí la vida misma de la pasión y la sinceridad (Capdevila 1928: 113-114)

Treinta y cinco años después, como se ha visto al comienzo, seguiría sosteniendo en la práctica esa peculiar convicción. 
La ponderación de la historia de los sefardíes y de la necesidad del estudio de su lengua y cultura y de su reconexión con el conjunto de la lengua española ocupa los siguientes dos ensayos en el libro, para los cuales se ha recuperado aquí el antecedente del segundo, "El castellano de los sefardíes, su romance", publicado en La Prensa el domingo 14 de febrero de 1926. El primer ensayo en el libro, "Los sefardíes". comienza nuevamente con el fundamento económico-político de la unidad de la lengua: "¿Cómo no ha de ser deseado, entre lo que más se anhela, la pureza del habla general y la comunicación de unas y otras naciones hispánicas mediante la difusión del libro de lengua española, si grandes son por muchas y variadísimas tierras, nuestros intereses espirituales, y todavía anda dispersa o se acabará de dispersar, si nada se hiciere, buena parte de la común familia?" (Capdevila, 1928: 123). Capdevila demuestra aquí un conocimiento al menos superficialmente amplio de la bibliografía existente, incrementado entre ambas publicaciones (la del periódico es de febrero de 1926, el libro aparece en 1928). Así, contradice las afirmaciones de Max Nordau recogidas por Pulido en su Españoles sin patria, acerca de la pobreza léxica del habla sefardí, contrastándolas con "averiguaciones recientes". Estas averiguaciones, en el artículo publicado en La Prensa, podían considerarse restringidas a las que declara en nota final (ausente en la edición en libro) como sus "fuentes principales" (Menéndez Pelayo, 1900; Pulido, 1905; Gil 1911), y a las que luego añadirá la referencia a Wagner (1914), sobre el cual lamenta que no pueda ser mejor conocido entre el público hispanohablante, ya que su libro estaba publicado en Viena y en alemán -aunque para entonces ya se contaba con contribuciones suyas en español y portugués (Wagner, 1923, 1924)- y a la Revista de la Raza de Manuel L. Ortega. En este mismo texto, junto a la fascinación por la supervivencia de la lengua y el acervo poético popular tras siglos de diáspora sefardí, se destaca su infantilización como recurso minorizador de los hablantes de la variedad (cfr. Heller, 2019).

Los últimos tres capítulos insisten con la unidad espiritual, con la retórica imperial hispanófila contra el avance norteamericano. En "En Manila se ha puesto el sol", publicado en La Prensa el 18 de julio de 1926, Capdevila pondera la grandeza imperial pretérita de España y retorna al clima de entresiglos, agitado por la guerra hispano-norteamericana, renovando la fórmula del nacionalismo hispanizante, al vincular ese pasado con el augurio de un futuro venturoso para Argentina:

Nosotros, por lo menos, queremos ser un pueblo de voluntad muy recia. De este modo, aceptamos sin el menor esfuerzo que en aquellas naves españolas se paseaba ya nuestro espíritu, según iba resonando nuestro idioma por nuevos y nunca surcados mares. (Capdevila, 1928: 151)

“La prodigiosa y díscola ciudad del idioma común", aparecido el 12 de junio de 1927 en La Prensa con el mismo título, abunda en la metáfora de la ciudad para referir al idioma, oponiendo al imaginario que evocaba el título del libro (el del "cosmopolitismo babélico" (Sarlo, 1996) demonizado por las élites dirigentes) el de una compleja y abigarrada comunidad de lengua. 
En el periódico, la intervención de Capdevila viene acompañada de una ilustración que adorna su firma y figura una ciudad luminosa, acorde con la descripción de la ciudad compartida por españoles y americanos que describe al comienzo, "ciudad alta, empinada sobre montes que miran al mar, muy esbelta, muy guarnecida, brillante al sol como si toda fuese de oro" (Capdevila, 1928: 167). El artículo celebra la "unidad espiritual" de "nuestra inmensa familia hispánica" (ibid.: 168) y vuelve sobre la polémica que en el cambio de siglos desatara el libro de Lucien Abeille (1900), actualizada entonces en los debates del día, desde Nuestra lengua de Costa Álvarez y la respuesta de Ernesto Quesada (1922) a ese mismo libro hasta las tensiones y polémicas generadas en torno a la instalación del Instituto de Filología de la Universidad de Buenos Aires en 1923 (Toscano y García, 2009, 2016), además de la inmediatez de la sonada encuesta del diario Crítica acerca de la posibilidad de un idioma nacional (Sztrum, 1998; Oliveto, 2010; Toscano y García, 2019; Ennis, Toscano y García y Santomero 2020) - el artículo de Capdevila aparece el 12 de junio de 1927, un día después de que lo haga la primera entrega de dicha encuesta. A tono con la dominante en la mayor parte de esas intervenciones (y entre ellas, la anteriormente mencionada de Borges, que tendría lugar tres meses después), esta actualización conecta, sin solución de continuidad, con el rechazo del lunfardo como base de una lengua local: "No, ya no hay quien dude entre la piltrafa de una lengua rioplatense, nacida de una jerga de ladrones, y esta hermosa solidaridad que nos vincula a millones y millones de hombres por toda la extensión del planeta" (Capdevila, 1928: 169). ${ }^{9}$ Luego de esto prosigue la lista de los "díscolos" de la lengua con la ya entonces plurisecular diatriba contra el galicismo, para pasar en la sección siguiente a la también recurrente queja por la falta de reciprocidad en el intercambio intelectual entre España y América, destacando la mayor importancia adquirida por Buenos Aires para la difusión del español, aun entre los hablantes de las demás lenguas de España: "En mira de Buenos Aires, no de Madrid, hay en este momento millares de hombres que aprenden castellano, así en Berlín como en Bruselas, así en el Japón como en el Canadá. En Buenos Aires, no en Madrid ni en Castilla entera, es donde se rinde al castellano el mayor número de gallegos, catalanes o vascos. Al Plata lo que es del Plata..." (ibid.: 172). De este modo, recriminando la poca receptividad hispánica para la producción intelectual americana, volverá a llamar al trabajo en la unidad americana, conjurando una hora de peligro inminente (ibid.:174) -en el que se adivina fácilmente el fantasma del imperialismo norteamericano- que demandaría tal unidad basada en el idioma común.

Resulta común a estas últimas columnas el recurso a la presentación del otro de la expansión de ese espíritu común del español como destinado a la desaparición, desprovisto justamente de esa capacidad de formar comunidad en el tiempo a través de la memoria común. Es el caso de las Filipinas, donde al recurso de la infantilización ("Chinos y malayos sueñan con alma cándida", ibid.: 153), se agrega el de esta carencia:

9. En la conferencia referida, Borges haría un razonamiento similar: "El lunfardo es un vocabulario gremial como tantos otros, es la tecnología de la furca y la ganzúa. Imaginar que esa lengua técnica -lengua especializada en la infamia y sin palabras de intención general- puede arrinconar al castellano, es como trasoñar que el dialecto de las matemáticas o el de la cerrajería puede ascender a único idioma" (Borges, 1998: 146-147). 
Tribus indígenas hay que viven como en el límite de análoga animalidad. No bajan nunca de la montaña. No les interesa la civilización. Épicos fueron los sucesos de la primera arremetida española. Magallanes mismo cayó a los golpes del indio. Reyezuelo hubo -el famoso Hamabar- que pudo considerarse el más glorioso capitán de su raza: el español, vencido, hubo de retirarse deshecho. Hamabar en Europa hubiera sido un héroe nacional y se le hubiera erigido estatua. En Cebú no fue así... Cuando a los cuarenta años de aquellos acontecimientos, los españoles retornaron, nadie recordaba nada, ni mozos, ni ancianos, ni sabía nadie cosa alguna de Hamabar (Capdevila, 1928: 154).

Esto se extiende a los pueblos originarios de América, donde la imagen del "inmenso mar del castellano" propicia la fantasía desbocada del homogeneísmo (Blommaert y Verschueren, 1998: 202204) u homo-hegemonía monoculturalista (Derrida, 1997: 105): de nuevo la metáfora más o menos evidente figura a las "antiquísimas lenguas de América" como silenciosas playas que se desvanecen ante el avance del idioma común. Su desaparición es también la de sus tradiciones e identidades: "A lo lejos, en el confín del horizonte, los apagados cráteres no son más que conos misteriosos. ¡Y no menos enigmáticos se elevan los monumentos que nadie sabe quién construyó! ¿Memorias de qué? Memorias de nada: son lo inmemorial. ¿Vaticinios de qué? Vaticinios de nada. Lo inmemorial carece de visión futura. Lo que no tiene memoria ignora la esperanza” (Capdevila, 1928: 186). Así, Capdevila recupera una imagen ya presente en Bello (v. Ennis y Pfänder, 2013: 62-63), la del monumento mudo, la damnatio memoriae que condena a la cultura del otro, junto con su lengua, a la ilegibilidad, en función de un progreso irrevocable:

¿Y las otras cien, y las otras mil lenguas aborígenes, de tribus, de clanes, de ayllus, que a manera de islotes se fue tragando el mar de la lengua nueva por todo lo que es América? Tal cataclismo espiritual fue aquel, que ese mismo de la sumergida Atlántida pálido parece a su lado.

Y todavía trabaja el mar, y lo que deba ser destruido, será destruido. [...] Hasta que todo sea mar: inmenso mar castellano. (Capdevila, 1928: 186-187)

Así el ensayo refuta en su cierre en todas las versiones, que será también el cierre del libro, lo postulado antes para Manila, reforzando la retórica imperial: "Y no se pone el sol” (ibid.: 189). 


\section{Consideraciones finales}

En estas páginas se ha procurado ofrecer una presentación y examen inicial de una serie de intervenciones que encuentran su manifestación más conocida en el volumen Babel y el castellano, pero que tienen su génesis en la prensa periódica y alcanzan un entramado institucional, material y discursivo complejo que integra el discurso y las instituciones de la literatura con las del discurso especializado sobre la lengua, la educación y la política. De este modo, el análisis propuesto para este corpus textual permite observar las diferentes y complejas alternativas de la circulación de este tipo de intervenciones sobre el lenguaje en el espacio público, desde el momento de su producción hasta las formas más tardías de su recepción.

Si bien la historia de los debates ideológico-lingüísticos en Argentina se abre desde las primeras décadas del siglo XIX, puede decirse que hasta los años 1920 esto no sucede a través de tradiciones sostenidas de intervención pública sobre la lengua, sino mediante la aparición de debates singulares en distintos momentos y de diversa intensidad y extensión. Es a lo largo de las décadas del 20 y 30 que puede observarse la emergencia y proliferación de formas diversas de la intervención pública sobre el lenguaje en la prensa escrita, y junto a procesos de institucionalización específicos (como la creación del Instituto de Filología de la Universidad de Buenos Aires en 1922 y la de la Academia Argentina de Letras en 1931), y la consolidación de firmas relacionadas directamente con la intervención en el espacio público del lenguaje, que a su vez empiezan a encontrar un lugar cada vez más notorio en un pujante mercado editorial. Esto no significa que en la exploración de la prensa escrita no podamos encontrar manifestaciones anteriores de este tipo de intervenciones, sino que es a partir de ese momento que se generan condiciones de posibilidad en varios aspectos para darle visibilidad y continuidad. Entre estos aspectos puede enumerarse de manera preliminar la complejidad del panorama de las competencias legítimas disponibles para intervenir sobre el tema a partir de la emergencia de espacios de profesionalización del saber sobre la lengua e incipiente formación de un campo científico relativamente autónomo, la extensión y diversificación de los periódicos metropolitanos (y del novedoso espacio de las conferencias públicas), y los rasgos específicos del desarrollo de la cultura impresa en Buenos Aires y la diversificación y tensiones en el campo literario.

Las dos escenas citadas al inicio, en las cuales Capdevila comparte el escenario con Borges, permiten, del lado de la literatura, observar el alcance y los límites del destacado lugar que asume un discurso de este tipo: cuando el joven escritor presenta en el escenario privilegiado del periódico más vendido de la época su discurso sobre la materia, la presentación será hecha por su firma más frecuente para esta temática; al mismo tiempo, cuando décadas después, en la Academia Argentina de Letras, Capdevila -aún en un plano destacado en las manifestaciones públicas de la cultura legítima- persista en sus afanes por corregir el español local y acercarlo al peninsular, será devuelto por ese mismo escritor, ahora de fama universal, discretamente al rincón de las preocupaciones baladíes. Esa parábola da cuenta bastante aproximada del destino de la firma de Capdevila en el 
horizonte de la literatura y los discursos legitimados sobre la lengua, desde la notoriedad de un escritor ampliamente reconocido hasta la reminiscencia anecdótica de un purismo militante.

Lo que el caso de Capdevila permite observar en la serie de textos aquí analizada es cómo en el momento en el cual emerge con fuerza la autoridad de un campo científico hegemonizado por los discípulos de Menéndez Pidal, del mismo modo que surgen formas de resistencia o alternativa frente a ese discurso hegemónico (Toscano y García, 2015, 2016), comienzan también a circular formas paralelas de autorización de un discurso sobre la lengua en el espacio público, propiciadas sobre todo por la prensa y su expansión y prestigio en la época - donde también encuentran lugar intervenciones provenientes de ese novedoso campo científico proveedor de autoridad discursiva en la materia, como es el caso por ejemplo con los artículos de Américo Castro en La Nación en la misma época. A partir de la articulación entre el discurso lego y el especializado (al menos al recurrir a este último como referencia obligada), entre el espacio de la prensa periódica y el mercado del libro, Capdevila logra agregar a su perfil de escritor los rasgos de un celoso y eficiente guardián de la lengua. Partiendo de su labor publicística en un diario de gran alcance, que articula con otra en los espacios que proporciona el propio periódico, sostiene su influencia en las sucesivas ediciones del libro, que logran incorporarse (a través de las incursiones de los lingüistas profesionales como A. Castro en la política lingüística, en la prescripción pura y dura) a una tradición presuntamente científica y le permiten ganar un alcance de otro modo difícil de imaginar para sus pareceres sobre la conducta lingüística de sus compatriotas. 


\section{Referencias bibliográficas}

Abeille, Lucien (1900), Idioma nacional de los argentinos, París, Bouillon.

Alemany, Carmen (1998), La polémica del meridiano intelectual de Hispanoamérica (1927). Estudio y textos, Alicante, Universidad de Alicante.

Alfón, Fernando (2013), La querella de la lengua en Argentina. Antología, Buenos Aires, Biblioteca Nacional.

Alonso, Amado (1943), Castellano, español, idioma nacional, Buenos Aires, Losada.

Arnoux, Elvira Narvaja de y Roberto Bein (1995), "La valoración de Amado Alonso de la variedad rioplatense del español", Cauce, nº 18-19, p. 183-194.

Benavides, Carlos (2003), "La distribución del voseo en Hispanoamérica”, Hispania, n 86, vol. 3, p. 612-623.

Blommaert, Jan y Jef Verschueren (1998). "The Role of Language in European Nationalist Ideologies", en Bambi Schieffelin, Kathryn Woolard y Paul Kroskrity (eds.), Language Ideologies. Practice and Theory, Nueva York y Oxford, Oxford University Press, p. 189-210.

Borges, Jorge Luis (1926), El tamaño de mi esperanza, Buenos Aires, Proa.

Borges, Jorge Luis (1998), El idioma de los argentinos, Buenos Aires, Alianza [1ª ed. 1928, Buenos Aires, M. Gleizer].

Borges, Jorge Luis (1962), “Discurso de Don Jorge Luis Borges en su recepción académica”. Boletín de la Academia Argentina de Letras, t. XXVII, nº 105-106, p. 303-312.

Bosoer, Sara (2008), 'Algo más que hispanismo-antihispanismo en la polémica por el meridiano: Lengua, nación y mercado a fines de la década de 1920', en Actas del I Congreso Internacional de Literatura y Cultura Españolas Contemporáneas, La Plata, Universidad Nacional de La Plata, 2008.

Capdevila, Arturo (1925), Tierras nobles. Viajes por España y Portugal, Buenos Aires, El Ateneo.

Capdevila, Arturo (1928), Babel y el castellano, Buenos Aires, Cabaut.

Capdevila, Arturo (1952), Despeñaderos del habla, Buenos Aires, Losada.

Capdevila, Arturo (1962), "Discurso de Don Arturo Capdevila en la recepción académica de Don Jorge Luis Borges”, Boletín de la Academia Argentina de Letras, t. XXVII, n 105-106, p. 297-302.

Capdevila, Arturo (1967), Consultorio gramatical de urgencia: Con algunos llantos y quebrantos o lances y percances del habla depor acá, Buenos Aires, Losada.

Carricaburo, Norma (1999), El voseo en la literatura argentina, Madrid, Arco. 
Castro, Américo (1941), La peculiaridad lingüística rioplatense y su sentido histórico, Buenos Aires, Losada.

Costa Álvarez, Arturo (1922), Nuestra lengua, Buenos Aires, Sociedad Editorial Argentina.

Costa Álvarez, Arturo (1928), Reseña de Babel y el castellano, de Arturo Capdevilla. Nosotros, vol. LXI, t. 22, n²3, p. 288-290.

Degiovanni, Fernando y Guillermo Toscano y García (2010a), "'Las alarmas del doctor Américo Castro': institucionalización filológica y autoridad disciplinaria”, Variaciones Borges, n 30, p. 3-42.

Degiovanni, Fernando y Guillermo Toscano y García (2010b), "Disputas de origen: Américo Castro y la institucionalización de la filología en la Argentina”, Nueva Revista de Filología Hispánica, vol. LVIII, no 1, p. 191-213.

Derrida, Jacques (1997), El monolingüismo del otro o la prótesis del origen, Buenos Aires, Manantial.

Del Valle, José (dir.) (2015). Historia política del español. La creación de una lengua, Madrid, Aluvión.

Ennis, Juan (2008), Decir la lengua. Debates ideológico-lingüísticos en Argentina desde 1837, Frankfurt et al., Peter Lang.

Ennis, Juan (en prensa), "La filología como profesión en la Argentina del 20: Arturo Costa Álvarez en la prensa", en Elvira Narvaja de Arnoux, Lidia Becker y José del Valle (eds.), Reflexiones glotopolíticas desde y hacia América y Europa, Berlín, Peter Lang.

Ennis, Juan y Stefan Pfänder (2013), Lo criollo en cuestión. Filología e historia, Buenos Aires, Katatay.

Ennis, Juan (2020), Guillermo Toscano y García y Lucila Santomero (eds.) (2020), La lengua argentina. Una encuesta del diario Crítica (1927), Santa Fe, Vera Cartonera.

Estrella Gutiérrez, Fermín (1962), Arturo Capdevila, Buenos Aires, Ediciones Culturales Argentinas.

Falcón, Alejandrina (2010a), "Un español sin patria ninguna: el idioma de los libros en tiempos de auge editorial", IX Congreso Argentino de Hispanistas, 27 al 30 de abril de 2010, La Plata. El hispanismo ante el bicentenario. Disponible en: http://www.memoria.fahce.unlp.edu.ar/trabeventos/ev.1069/ev.1069.pdf

Falcón, Alejandrina (2010b), "El idioma de los libros: antecedentes y proyecciones de la polémica "Madrid, meridiano 'editorial' de Hispanoamérica"', Iberoamericana, vol. X, n³7, p. 39-58

Fontanella de Weinberg, María Beatriz (1971), "El voseo en Buenos Aires en las dos primeras décadas del siglo XIX”, Thesaurus, vol. XXVI, n. ${ }^{\circ}$ 3, p. 495-514.

Fontanella de Weinberg, María Beatriz (1976): "Analogía y confluencia paradigmática en formas verbales de voseo”, en Thesaurus, vol. XXXI, n.ㄹ 2; p. 225-239. 
Gagné, F., Verreault, C., Mercier, L. (2004), “La base de données textuelles ChroQué: un nouvel outil pour élargir la description du français en usage au Québec", en Mercier, L. (ed.), Français du Canada - Français de France. Actes du sixième colloque international tenu à Orford, Québec, du 26 au 29 sept. 2000, 247-261. Tübingen: Niemeyer.

Gil, Rodolfo (1911), Romancero judeo-español, Madrid, Imprenta Alemana.

Glozman, Mara (2015), Lengua y peronismo. Políticas y saberes lingüísticos en Argentina, 1943-1956, Buenos Aires, Biblioteca Nacional.

Gómez, Hernán E. (2008), Los diarios como espacios públicos: La Prensa en la vida social de Buenos Aires a comienzos del siglo XX, Intersecciones en Antropología, n 9, p. 261-274.

Heller, Monica y Bonnie McElhinny (2017), Language, Capitalism, Colonialism. Towards a Critical History, Toronto, Toronto University Press.

Heller, Monica (2019), "Sociolinguistic Frontiers: Emancipation and Equality", Items. Insights from the social sciences, disponible en https://items.ssrc.org/sociolinguistic-frontiers/sociolinguistic-frontiers-emancipation-and-equality/

López García, María (2015), Nosotros, vosotros, ellos. La variedad rioplatense en los manuales escolares, Buenos Aires, Miño \& Dávila.

López-Morell, Miguel Ángel y Antonio Molina Abril (2012), "La Compañía Iberoamericana de Publicaciones, primera gran corporación editorial en castellano", Revista de Historia Industrial vol. XXI, n. 49, p. 111-145.

Ludmer, Josefina (1999), El cuerpo del delito. Un manual, Buenos Aires, Perfil.

Malmberg, Bertil (1973), "La situation linguistique de la République Argentine et du Río de la Plata”, en Linguistique générale et romane. Études en allemand, anglais, espagnol et francais, La Haya y París, Mouton, p. 319-334.

Meier, Franz y Sabine Schwarze (2020, en prensa), "CROM.net - una investigación de corpus contrastiva en torno a la epistemicidad y las tradiciones discursivas en las columnas del lenguaje en lenguas romance", en G. Goldchluk y J. Ennis (eds.), Las lenguas del archivo. Filologías para el siglo XXI, La Plata, EdULP.

Menéndez Pelayo, Marcelino (1900), Antología de poetas líricos castellanos, tomo X: Romances populares recogidos de la tradición oral, vol. III, Madrid, Viuda de Hernando.

Oliveto, Mariano (2010), "La cuestión del idioma en los años veinte y el problema del lunfardo: a propósito de una encuesta del diario Crítica”, Revista Pilquen vol. XII, n.ำ13, p. 1-9.

Pulido Fernández, Ángel (1905), Españoles sin patria, Madrid, Teodoro.

Quesada, Ernesto (1922), La evolución del idioma nacional, Buenos Aires, Mercatali. 
Remysen, Wim (2005), "La chronique de langage à la lumière de l'expérience canadienne-française: un essai de définition", en Remysen, Wim et al. (eds.), Les Journées de linguistique. Actes du $18^{e}$ colloque 11-12 mars 2004, Quebec: Centre interdisciplinaire de recherches sur les activités langagières, p. 267-281.

Remysen, Wim (2009), Description et évaluation de l'usage canadien dans les chroniques de langage: contribution à l'étude de l'imaginaire linguistique des chroniqueurs canadiens-français, Quebec, Université Laval.

Saítta, Sylvia (2013 [1998]), Regueros de tinta. El diario Crítica en la década de 1920, Buenos Aires, Siglo XXI.

Sarlo, Beatriz (1996), "Oralidad y lenguas extranjeras. El conflicto en la literatura argentina durante el primer tercio del siglo XX", Orbis Tertius vol. 1, n. ${ }^{\circ}$ 1, disponible en https://www.orbistertius.unlp. edu.ar/article/view/OT

Sztrum, Marcelo (1992), "Algunas relaciones entre 'lengua gauchesca' e 'idioma nacional de los argentinos', América. Cahiers du CRICCAL, n. ${ }^{\circ} 11$, p. 62-77.

Sztrum, Marcelo (1998), "¿Llegaremos a tener un idioma propio? Encuesta en el diario Critica, Buenos Aires, 1927", América: Cahiers du CRICCAL. Polémiques et manifestes auX XIXe et XXe siècles en Amérique latine, n²1, p. 219-225.

Torre, Guillermo de (1927), "Madrid, meridiano intelectual de Hispano-América", La Gaceta Literaria, ibérica, americana, internacional. Letras, artes, ciencia, t. I, n. ${ }^{\circ}$ 8, p. 1.

Torre, Guillermo de (1932), "Nuestro idioma y la Argentina. Babel y el castellano", El Sol XVI, 4623, 5 de junio de 1932, p. 8.

Torre, Guillermo de (1940), "La buena doctrina", en Capdevila, Arturo. Babel y el castellano, Buenos Aires, Losada, p. 165-171.

Toscano y García, Guillermo (2009), "Materiales para una historia del Instituto de Filología de la Universidad de Buenos Aires (1920-1926)", Revista Internacional de Lingüística Iberoamericana, vol. VII, n. ${ }^{\circ} 13$, p. $113-135$.

Toscano y García, Guillermo (2015), “'Antes que mentir exclusividad que no siento'. Saberes lingüísticos e instituciones reguladoras en Delfina Molina y Vedia", Estudios de Lingüística del Español, n. ${ }^{\circ} 36$, p. $25-56$.

Toscano y García, Guillermo (2016), "Debates sobre la lengua e institucionalización filológica en la Argentina durante la primera mitad del siglo XX”, en José del Valle (ed.), Historia política del español. La creación de una lengua, Madrid, Aluvión, p. 245-265.

Toscano y García, Guillermo (2019), "El futuro de la lengua, la lengua del futuro. Sobre la encuesta del diario Crítica (1927)", Olivar vol. 19, n. ${ }^{\circ} 29$, https://doi.org/10.24215/18524478e052 
Unamuno, Miguel de (1940), "Prólogo con versos”, en Arturo Capdevila, Babel y el castellano, Buenos Aires, Losada, p. 11-12.

Vidal de Battini, Berta Elena (1964), El español de la argentina. Estudio dedicado a los maestros de las escuelas primarias, Buenos Aires, Consejo Nacional de Educación.

Wagner, Max Leopold (1914), Beiträge zur kenntnis des Judenspanischen von Konstantinopel, Viena, Hölder.

Wagner, Max Leopold (1923), "Algunas observaciones generales sobre el judeo-español de Oriente", Revista de Filología Española, n. ${ }^{\circ}$ 10, p. 225-244.

Wagner, Max Leopold (1924), "Os judeos hispano-portugueses e a sua língua no Oriente, na Holanda e na Alemanha", Arquivo de história e bibliografia, vol. I, p. 257-272.

Zeballos, Estanislao (1915), "Acta de fundación del Instituto Popular de Conferencias", Anales del Instituto Popular de Conferencias Dr. Lisandro de la Torre, c. I, p. 3-6. 